\title{
Charting ASHS's Course: End of the First \\ Century and Beyond
}

\section{Presidential Address ${ }^{\mathrm{T}}$}

\author{
M. Allen Stevens \\ ASHS President. 1992-93
}

The American Society for Horticultural Science has a long and distinguished history. Since its creation 90 years ago, it has done much to promote science in horticulture. Its Proceedings, Journal, and HortScience have been purveyors and repositories of much of the important information in horticultural science, and its annual meetings have provided excellent opportunities for information exchange and the genesis of ideas.

As the Society sails toward its centennial, the seas are rough and strong winds of change are blowing. What course should ASHS set to assure continued vitality and outstanding contributions to science in horticulture?

The Strategic Planning Committee (SPC) has evaluated where members want the Society to go and what they want it to be in the future. The committee has deliberated with an understanding and appreciation of ASHS's history and tradition-for only by noting where we came from can we forecast where a new course will take us.

Horticulture departments have changed and continue to change. ASHS must change also. While we must appreciate and use ASHS traditions that will continue to serve horticultural science well, we also should be bold enough to forge a plan that will avoid a loss of relevance for the Society. When I joined the Dept. of Vegetable Crops at the Univ. of California at Davis $\approx 23$ years ago, virtually every member of that department believed he was a horticulturist, and most were active in ASHS. Not so today. Many of the newer members of that department are not ASHS members. They consider themselves molecular biologists, physiologists, or geneticists, not horticulturists. An extreme example? A harbinger of things to come?

Most organizations have a life cycle. They have a vigorous and flexible youth, an age of growing strength, and an old age of decline. A few organizations are timeless. They either change with the times or have a role that is so broad and basic that they are minimally affected by changes going on around them. To

\footnotetext{
Presented at the 90th annual meeting of the American Society for Horticultural Science, Nashville, Term., 28 July 1993.

Viewpoints are published in HortScience to provide members of the American Society for Horticultural Science an opportunity to share their experiences and comments on matters of concern to horticulturists. These are not statements of official Society policy, nor do they necessarily reflect the views of a majority of the Society's members.

${ }^{2}$ Petoseed Co., Inc., Woodland, Calif.
}

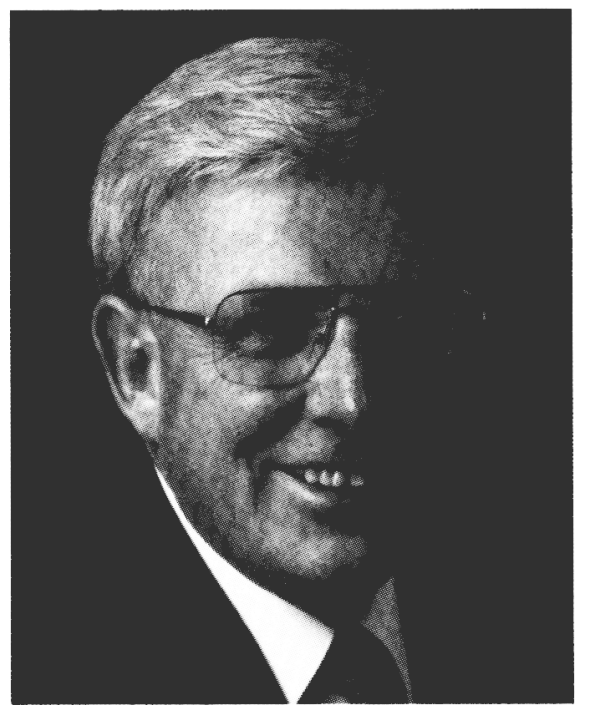

avoid decline, I believe ASHS must proactively address the changes that are impacting horticultural science.

ASHS has changed since its inception. For the first 61 years, the Society was managed mostly by a cadre of dedicated volunteers. It was not until 1964 that the first executive director was hired. The organization of the Society also has changed. Until 1969, there were one discipline and three commodity sections, i.e., postharvest, pomology, vegetable crops, and floriculture. That year, the education and extension sections were added. In 1976, the Society was reorganized into four divisions-research, education, extension, and industry. In 1982, an International Division was added. Adding two sections and reorganizing into five divisions was done to better serve the Society's diverse membership. Although this may have been partially successful, there still is much to be done.

Working groups were formed in 1977 to address member specialties. There seems to be wide agreement that the initiation of working groups was an excellent move. ASHS will survive by continuing to serve its changing audience, as it has for the past 90 years; by continuing to do what it has done well-to serve primarily as a networking institution for public horticultural researchers. I doubt that it will flourish if it does not continue to change at an accelerated rate.

\section{WHAT IS HORTICULTURAL SCIENCE?}

A focal point of the SPC discussions revolved around the issue of diversity. The no- tion of nurturing the diversity that is horticultural science was a key, time-consuming concern. I was surprised at the narrow-minded views expressed in several surveys as to what constitutes horticultural science and who is a horticultural scientist. Many presidential addresses, recent and not so recent, have briefly pondered, "What is horticultural science?" The following are slightly paraphrased versions of a few answers to that question.

John Carew (1966) - The horticulturist lays the same bricks as the biochemist, the geneticist, the plant physiologist, and the botanist. He uses the same growth chamber, the same scintillation counter, the same microscope. He grows many of the same plants. But horticulture is plant science with a $h u$ man goal. When the technique becomes more important than the plant, when the scientific paper is a greater reward than an answer to our problem or the gratitude of mankind, and when we are content to have our knowledge gather dust in a library and are no longer interested in communicating with those who produce or use our plants, then horticulture will be dead.

Henry Munger (1967)-Be a physiologist, a geneticist, a chemist, but also take pride in being a horticulturist.

W.A. Frazier (1969)-Horticulturists piece together, synthesize, integrate, predict, cooperate, and research to whatever depth necessary to manipulate growth, harvest, storage, processing, transport of fruit, vegetable, and ornamental plants for foods, and the aesthetic needs of man. We must continue to specialize to gain vertical knowledge of the behavior of species and varieties.

Ed Proebsting (1984)_-Horticulture is an agricultural science that deals with amenities, the good things in life. It is very important for us to recognize that our niche as horticultural scientists may be quite different than either superior plantsmen or Nobel prize-winning scientist.

James Moore (1988)-There are those, of course, who maintain that the research horticulturists cannot be basic because we deal with economic plants and solve practical problems. One has only to consider the many contributions to the basic knowledge of plant science 
made by horticulturists in such areas as genetics, physiology, plant growth regulation, flowering, and fruiting to see the fallacy of such thinking.

Jules Janick (1988)—There was no illusion then (1903), as now, that horticulture itself was science, but there was faith that there was a horticultural science. Our Society was founded on the proposition that though horticulture was an art, there was and ought to be science in horticulture. Horticulture is to botany as electrical engineering is to physics. Liberty Hyde Bailey was critical of the purely applied in horticulture. He censured his fellow horticulturists and urged them to specialize in their respective disciplines. I believe that the tension generated by the conflict between science and horticulture, rather than a fatal flaw, is our strength. It keeps us honest, it keeps us relative, and it keeps us attuned-both to the world of science and to the worlds of agriculture and commerce.

\section{KEY RESULT AREA (KRA) 1- SERVING A DIVERSE MEMBERSHIP}

Diversity is the key to success for ASHS. Diversity is our strength because it broadens our membership base while expanding the areas of discussion within the organization. Our advantage is the bridge the Society provides between fundamental and practical horticulture. This requires diversity to succeed.

Diversity also is our weakness when we show an inability to serve equally the needs of the various constituencies of our diverse membership. The Society serves its core constituency well, but it needs to better serve teachers, extensionists, and commercial scientists.

Traditional horticulturists are becoming fewer, and research is becoming more specialized and discipline-oriented. With this specialization and narrowing, how can ASHS be more valuable to the less active and the new horticultural scientists? Many new members of horticulture departments do not have any alliance with or allegiance to ASHS. Who will be the members of ASHS in 10 years? I believe that since fundamental research will come largely from public scientists, we need to assure that the membership includes the best public scientists in this profession. The Society will be more successful if it can be more "boundaryless" in its thinking and actions. Boundarylessness is behavior that involves bringing people outside their conceptual boxes and working together to address problems and develop solutions. It can empower people to do their best for the entire organization rather than focusing on their confined niche.

To communicate high-quality research is the principal reason for ASHS's existence. There has been divergence of opinion concerning the Society's publication priorities: some feel that a more discipline-oriented approach should be pursued to attract the new horticulturists, while others prefer stressing more practical reports. I believe our central role is to bridge the gap between plant biology and practical horticulture. Our publications should connect basic discipline-oriented research with the art of horticulture. This is our competitive edge, our high ground. If we can till this need with class and clarity, ASHS's future will be secure. Assuming our publications, working groups, and meetings have high quality, and that we succeed in serving the needs of our diverse membership, the Society will not only survive, but also flourish.

\section{Details}

How many periodicals does ASHS need to accomplish this purpose? I often wonder if we can afford to have three periodicals. plus a newsletter-not only in the financial sense, but also because we lose part of the coupling aspect of our diversity. It is possible that we would be better served with a restructured Journal and HortScience. This would require rethinking editorial policy to continue to assure and improve quality while serving the interests, concerns, and needs of a diverse membership.

Perhaps the Society should become a leader in developing and using new methods of disseminating information. What if a new information highway was developed where members would access only those articles that were of interest to them? Could there be a market for publishing "packet" periodicals where the main (common) discussion and synopsis of all articles goes to each ASHS member along with the full articles in areas that they have selected previously? What about the "bulletin board system"- - using modems to access published articles electronically?

These possibilities and others deserve our consideration as we look for new ways to improve service at a reduced cost.

\section{Obstacles}

There are other considerations that will contribute to the future success or failure of ASHS. Research interests have so dominated this Society in the past that individuals who are not academic researchers sometimes feel like second-class citizens. I firmly believe that we must provide additional opportunities to other segments of our existing and potential membership. My hope is that we can do that while continuing to provide excellent opportunities for the core segment.

Part of this problem is that some ASHS members need to be more inclusive in their definition of a horticultural scientist. Our profession involves all kinds of science. The debate on discipline vs. commodity orientation is nonsensical to me. Many horticultural scientists are discipline-oriented one second and crop-oriented the next.

\section{KRA 2-ORGANIZATION}

Large organizations are usually very bureaucratic, yet many of their leaders profess a desire to eliminate bureaucracy and emulate some of the characteristics of successful small organizations. Positive characteristics of small organizations include being uncluttered, simple, and informal; embracing good ideas regardless of their source; involving everyone; and communicating with simple arguments rather than jargon-filled memos. What most differentiates small organizations from large ones is speed, which brings an urgency and exhilaration. I believe speed results in focusing on what really matters. Bureaucracy brings with it orderliness and a collection of rules. Nonbureaucratic organizations may be more chaotic, but they also may be more productive. ASHS is too orderly. Dissidents are branded as malcontents and largely ignored. There are times when the Society appears more like an old boys club than a scientific society-tradition sometimes seems honored for its own sake rather than for what it accomplishes.

ASHS's problem with bureaucracy is shown in its lack of responsiveness to members. The controversy over scheduling annual meetings is an example. In 1973 a group of Society members, including plant breeders, requested that periodic fall meetings alternate with the traditional summer meeting. Nineteen years later, after much cajoling and a false start or two, the Board finally approved that, after 1994, one-half of annual meetings will be held after 15 Sept. I am sure there are many reasons it took almost 20 years to make this decision, but the arguments for summer meetings never persuaded me that we should not give fall meetings at least an opportunity.

The gap between the Board of Directors and the membership is a serious problem. The Board frequently is perceived as a group of narrow-minded individuals-a good old boys network, who neither listen to nor adequately address the concerns of the membership. The surveys indicated that the Board of Directors has lost touch with the members. The Board was seen as being insulated and not trying to understand nor respond to members' concerns.

Responsiveness does not imply that everyone gets whatever he/she wants. Responsiveness implies a mechanism for dialog between members, and serious consideration of member desires. Responses should be in the form of changes that benefit a significant proportion of the membership with minimal effects on the benefits provided to other members.

\section{Member input}

So many men, so many minds; So many minds, so many ideas; So many ideas, so much talk; So much talk, so much confusion; So much confusion, so much delay.

Lloyd George, from Davis (1956)

There is a tendency in an organization such as ASHS for individuals in power to want to get on with it. "Damn the torpedoes, full speed ahead!" Because the tenure for elected officers is short, new officers can easily feel a sense of urgency and become convinced that too much input, too much debate will spoil their chances for making a recognizable impact. Perhaps 
because individual members are seen as powerless in the organization, a person who becomes an officer may feel "I can finally make a change !" and act precipitously; thus perpetuating the tendency to ignore the broad general membership.

This is not an immutable condition!

There may have been a tendency for the Boards to minimize members' complaints or to develop agendas that fit personal perceptions based on personal experiences. And highly vocal-members may have had an inordinate impact on decisions because it was complicated to seek and obtain broader member input, but we do not need to extend this pattern into the future.

The Society needs a system to gamer member input, and the ASHS Newsletter is an excellent medium for that purpose. There is obviously considerable member apathy in ASHS, as in most other associations, and many members will not respond no matter what we do. But even a $15 \%$ membership response is much better than no input at roll, especially since that percentage, whatever it maybe, will include those members who want to make their wishes known.

\section{Finances}

Another major issue is our finances. In the past 2 years, our budget has not fared well. New programs that were started recently had optimistically unrealistic assessments of their costs and income potential. In 1992, the Board was forced to slow down some programs and put other programs and proposals on hold before their efficacy was known.

It has been suggested that ASHS is pricing itself out of business. There are fewer scientists, but numerous new programs. Is this sustainable? We should not increase further membership dues, meeting registration, or page charges to solve the Society's financial stress. Our fees are already higher than those of several comparable societies. Rather, we must focus efforts on those programs that are most important to our mission and that are most desired by the membership. The operative words should be focus and efficiency.

\section{KRA 3-PROMOTING HORTICULTURE}

Our certificate of incorporation outlined four purposes for ASHS: 1) sponsorship of an annual meeting, 2) dissemination of horticultural knowledge through publications, 3) leadership in horticultural matters, and 4) development of mutual understanding among individuals and organizations concerned with horticulture. Obviously, the Society has actively pursued purpose 1 and 2 . I believe we have treated 3 and 4 only superficially. Greater attention to them could significantly benefit horticultural science.

Another KRA identified in strategic planning is promote horticulture. A start was made in promoting horticultural science when a public relations director was hired in 1992. This is a modest beginning, but it will bean expensive effort; although I believe, in the long term, it will be a productive undertaking. Identifying several arenas where an effective and modest public relations effort can help horticultural science is easy. Such an effort can 1) attract students to horticulture, 2) attract new members to ASHS, 3) improve public understanding of the contributions of our science, 4) increase subscriptions to periodicals, and 5) increase advertising in periodicals.

ASHS has not "sold" horticulture, and some believe that the Society has to make a greater effort to tell our story. A frequently heard lament from member surveys is that people do not understand horticultural scientists or our contributions to the physical and mental well-being of humankind. I believe that the best way to improve people's perceptions of horticulture and to attract more students is to promote horticultural science and our Society more effectively. One suggestion I like is that selected authors should write popular news releases of significant research findings for communicating our contributions to the general public.

An outreach to like-minded societies and groups with different agendas could provide guidance on addressing the needs of changing clientele. Some suggest that we have not adequately addressed the needs of urban populations or the demand by consumers for improved quality, recognized the importance of nontraditional consumer-based horticulture, served the needs of a horticultural industry, nor recognized the stronger role of nonacademic production research. The upswing and importance of environmental issues and the need to minimize chemical inputs and adverse affects of agriculture are issues that need greater attention.

Are there mechanisms for ASHS and its membership to address these and other issues? Several approaches are being proposed by the action teams for KRA 3.

\section{Growth}

Follow with me the changes in ASHS membership over the years. There was rapid growth for $\approx 20$ years following World War II, then a plateau in membership for slightly less than a decade, followed by a growth spurt from 1976 to 1980. Several theories have been proposed to account for the large increase in membership during this period; some believe that the creation of working groups was a significant factor in this growth spurt; others argue that this was a period of growth for horticulture departments because of increased student populations. The growth probably resulted from a combination of events. Since the early 1980s, membership numbers have been largely unchanged. With all of the downsizing and consolidation that has occurred in horticulture departments, perhaps what is surprising is that membership has not declined in recent years.

A reasonable conclusion is that it would be easier for the Society to spread its wings if membership increased. Growth could provide the resources needed to start new programs that would help promote science in horticul- ture, which, in turn, would attract new potential members. I think that if membership declines or remains constant, new programs will have to be minimized unless new and innovative ways to reduce costs are found.

There are probably thousands of potential new ASHS members, but what changes must ASHS make to attract them? Are these changes acceptable to present members? Are they compatible with our mission? A sustained modest growth in membership is necessary for the Society to continue as a vital organization. To achieve this will be a real challenge that will require recruiting and sales efforts by present members.

\section{A STRATEGIC BEGINNING}

We have made a small beginning, relative to the task ahead, in developing a strategic plan that has the potential to act as a significant rudder for future leadership to guide the Society. Strategic planning is an iterative process; it is effective only if it is ongoing. If ASHS can continually evaluate and revise this strategic plan and refine and revise action plans as they are accomplished, then this plan can have a strong positive impact.

Getting all of the strategies and action plans right the first time is not nearly as important as getting started with strategic thinking. We should have a coherent and defensible basis for decision-making by the volunteer leadership that changes frequently. The key is to make today's decisions in light of the potential consequences on the future of ASHS.

As this plan is discussed in the Society, a sizable portion of the membership probably will argue that things are okay as is and that no change is needed or desired. The axiom that change has no constituency may not apply completely, but I will bet that there will be plenty of advocates for the status quo-there usually are.

Perhaps the most important accomplishment in this strategic planning process has been a reaching out to members and potential members to determine where the Society is today and where it should be going in the future. A lot of time and resources were spent to garner as much member involvement as possible for this planning.

The difficult task of translating ideas into actions has started, but making the changes needed to keep the Society healthy and vigorous into the future will not be easy. Action steps identified to implement the strategic plan probably will largely promote short-term goals that lead to the plan's larger, long-term goals. Frequently looking afresh at action plans probably will be the most effective way to keep ourselves on track.

The challenge seems clear to me. It is time to scrape the barnacles off the hull of the good ship ASHS, to cast overboard those entrenched practices that no longer serve the needs of the membership well, and to refine and lock down those that currently serve science in horticulture well. We need to take well-considered, bold, new initiatives to serve the Society's diverse membership better and to attract new 
members. If we can do this, the Society will sail smoothly past its first century and beyond. The importance of ASHS's role has increased since its founding; it has not diminished one iota in the present turbulent times. The promotion of science in horticulture is surely as important today as it was 90,50 , or 10 years ago. As populations increase and environmental quality declines, our contributions to food for the body and soul of humankind become increasingly important. I am confident that the dedicated members of this Society will assure its continuing success.

\section{References}

Carew, J. 1966. The composition of horticulturists. Proc. Amer. Soc. Hort. Sci. 89:766-772.

Davis, M.B. 1956. Education and research in the field of horticulture. Proc. Amer. Soc. Hort. Sci. 68:605-610.
Frazier, W.A. 1960. Horticulture's issues in education, science, communications, philosophy, politics and human welfare. HortScience 4:276-284.

Janick, J. 1988. Horticulture, science and society. HortScience 23:11-13.

Moore, J.N. 1988. Horticultural science in a changing world. HortScience 23:799-803.

Munger, H.M. 1967. Interactions and horticultural science. Proc. Amer. Soc. Host. Sci. 91:899-904.

Proebsting, E.L., Jr. 1984. Life in the slow lane. HortScience 19:615-617.

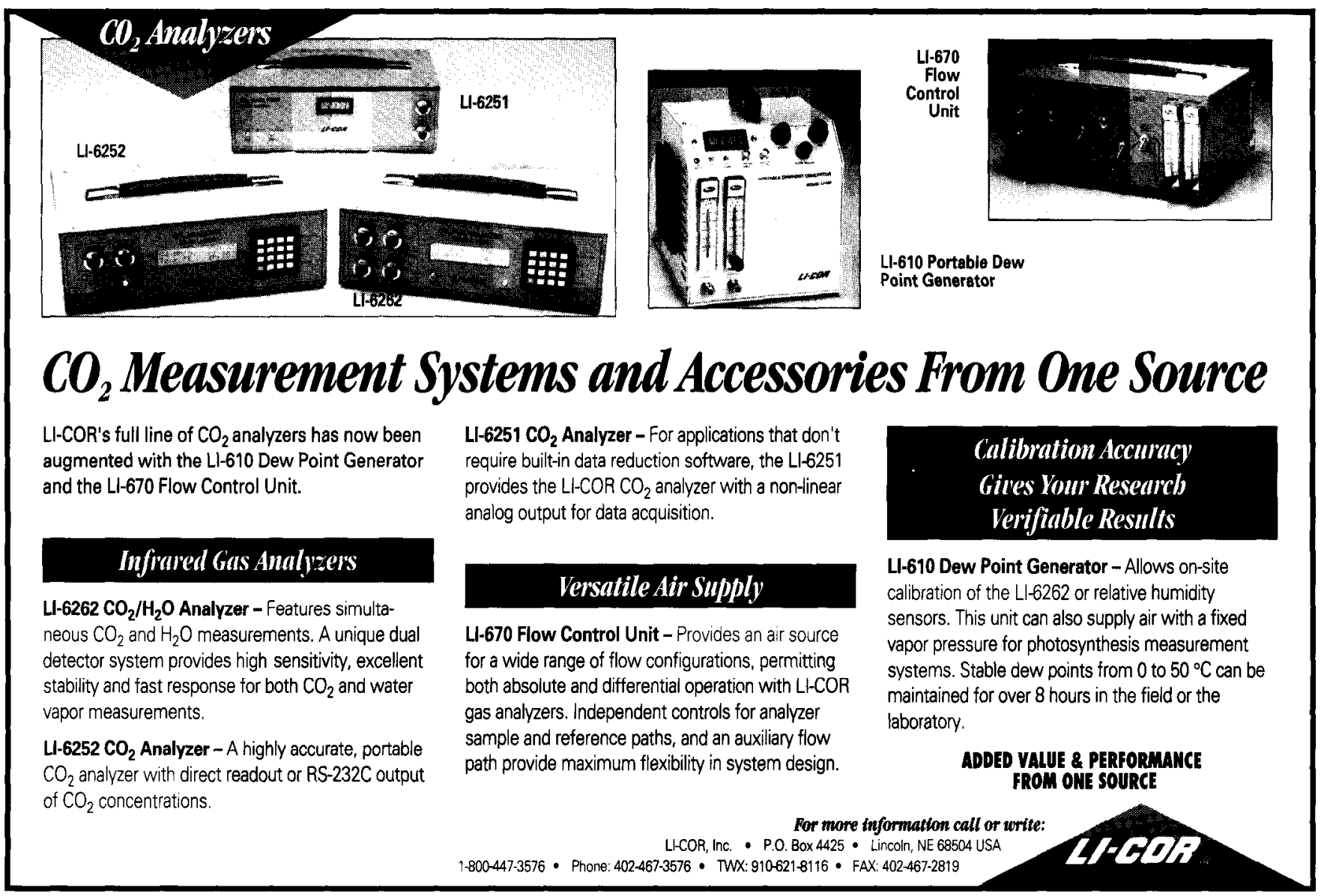

